\title{
Sex differences in the magnitude and practice decrement of the Müller-Lyer illusion'
}

\author{
ROBERT E. DEWAR \\ THE UNIVERSITY OF CALGARY
}

A comparison was made between male and female Ss on the magnitude and practice decrement of the Muller-Lyer illusion. Over a series of 400 trials, female Ss showed a slightly (but not significantly) higher illusion than did males. Male Ss showed a more rapid practice decrement than did females. The results were discussed in terms of field-dependence and attention.

Investigations of the Müller-Lyer illusion have, in general, not been concerned with individual differences. This is surprising in view of the rather high variability in susceptibility to this illusion. If one considers this to be a context illusion, in which the errors in judging the length of a line are caused by the distracting influence of the arrowheads, it would be predicted that females are more susceptible to the illusion than males. This is because they are more field-dependent (Witkin, 1949). This personality dimension of field dependence-independence refers to individual differences in ability to separate an object from its context.

Gardner (1957) found that Ss with greater fielddependence have greater susceptibility to visual illusions. Pressey (1964) reported that the magnitude of the Poggendorff illusion is correlated with performance on the embedded figure test (a measure of fielddependence).

Male Ss have been shown to be superior in ability to find hidden figures in the embedded figure test (Bieri, Bradburn, \& Galinsky, 1958; Newbigging, 1954). It has been proposed that males are better at this task because of superiority in analytic perception and thinking (Bieri et al, 1958). Work by Dewar (1967c) suggests that the formation of an "analytic attitude" brings about a reduction in the magnitude of the Muiller-Lyer illusion with practice. If this is the case, one would expect males to overcome the illusion with practice more rapidly than females. On the basis of these findings, it is predicted that females will have a greater initial illusion and overcome the illusion less rapidly with practice than will males. The present paper reports an investigation of this problem.

\section{Method}

The data on which this report is based were gathered in three experiments by the author (Dewar, 1967a, b). The Ss were students from an introductory psychology course. All Ss judged the Müller-Lyer figure 400 times (100 times per day on four consecutive days). A total of 92 Ss (46 males and 46 females) participated.
The apparatus consisted of a rectangular wooden panel $48 \times 26$ in., to the center of which was attached the stimulus (the Müller-Lyer figure). The horizontal segment of the figure was $20 \mathrm{~cm}$ in length. The oblique lines varied in length and the angle which they formed, depending on the experimental condition. The conditions were: $3 \mathrm{~cm}$ oblique lines forming an angle of $60^{\circ}(\mathrm{N}=$ 64); $3 \mathrm{~cm}$ oblique lines forming an angle of $120^{\circ}$ $(\mathrm{N}=12) ; 1 \mathrm{~cm}$ oblique lines forming an angle of $60^{\circ}$ $(N=16)$. Equal numbers of male and female ss were in each condition. Through a series of strings and pulleys the center arrowhead of the figure could be moved in either direction by $\mathrm{E}$ or by $\mathrm{S}$. Details of the apparatus and procedure are described elsewhere (Dewar, 1967b). The $\mathrm{S}$ was instructed to adjust the center arrowhead so that the two horizontal segments of the figure appeared to be equal in length. At the beginning of each trial the adjustable center arrowhead was set by $E$ obviously too far to the left or to the right of the center position.

\section{Results and Discussion}

The trials were divided into blocks of 10 for the purpose of analysis. There was no significant sex difference, although females had a slightly greater illusion on most blocks of trials (Fig. 1). There was a practice decrement over the series of 400 trials, as indicated by the analysis of variance $(F=12.85$, $\mathrm{df}=3 / 3510, \mathrm{p}<.001)$, as well as a significant trials by sex interaction ( $F=1.96, \mathrm{df}=39 / 3510, \mathrm{p}<.01$ ). This indicates that for male $\mathrm{Ss}$ the illusion reduced more

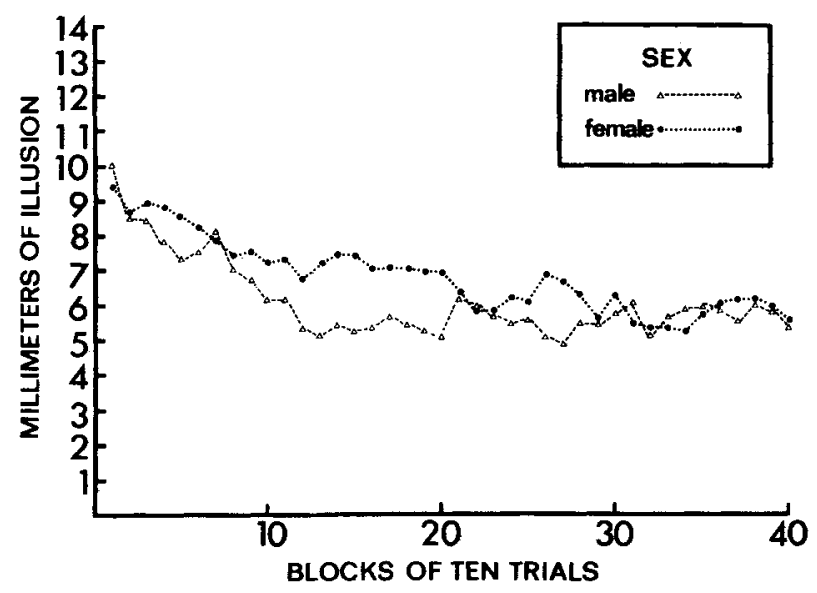

Fig. 1. Magnitude of the Milller-Lyer illusion as a function of practice and sex of $S$. 
rapidly than it did for females. The males dropped to an asymptotic level after approximately 120 trials, whereas the females continued to decrease more slowly for approximately 300 trials, at which point they reached the same level as the males. For neither group did the illusion disappear.

On the basis of these findings, one prediction was confirmed (the illusion will reduce more rapidly for males) while the other was not (females will show a greater illusion than males).

It appears that male and female Ss are equally susceptible to the distracting influence of the oblique lines of the Müller-Lyer figure, but males are more readily able to overcome this influence. In terms of Dewar's (1967c) interpretation of the practice decrement of the illusion, male Ss are quicker to develop an analytic attitude toward the task. This results in closer attention to the horizontal segment being judged. These findings are consistent with sex differences found on other perceptual tasks involving field-dependence and attention, such as the embedded figure test.

\section{References}

BIERI, J., BRADBURN, W. M., \& GALINSKY, M. B. Sex differences in perceptual behavior. J. Pers, 1958, 26, 1-12.

DEWAR, R. E. Effect of length of oblique lines and prominence of the horizontal line on the decrement of the Muller-Lyer illusion with extended practice. Psychon Sci, 1967a, 8, 509-510.

DEWAR, R. E. The effect of angle between the oblique lines on the decrement of the Müller-Lyer illusion with extended practice. Percept. \& Psychophys, 1967b, 2, in press.

DEWAR, R. E. Stimulus determinants of the practice decrement of the Müller-Lyer illusion. Canad. J. Psychol, 1967c, in press.

GARDNER, R. W. Field-dependence as a determinant of susceptibility to certain illusions. Amer. Psychol,, 1957, 12, 397. (Abstract)

NEWBIGGING, P. L. The relationship between reversible perspective and embedded figures. Canad. J. Psychol, 1954, 8, 204208.

PRESSEY, A. W. Group differences on the Poggendorff illusion. Paper presented at the 26th annual meeting of the Canad. Psychol. Assoc., Vancouver, June, 1965.

WITKIN, H. A. Sex differences in perception. Trans. N. Y. Acad. Sci, $1949,12,22-26$.

Note

1. This research was supported by Defence Research Board of Canada Grant No. 9425-18 and National Research Council of Canada Grant No. APA-141. 